Military Technical College Kobry El-Kobbah, Cairo, Egypt.

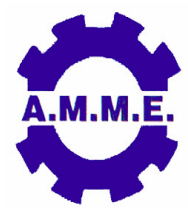

$15^{\text {th }}$ International Conference on Applied Mechanics and Mechanical Engineering.

\title{
RISK MANAGEMENT IN THE AVIATION GROUND LING (EGS COMPANY CASE STUDY)
}

T. Fouad

\begin{abstract}
Management of preceived risks in the business is considered one of the international standards to evaluate the performance of the organization. So, the aviation industry tended to this area from the eighties of the last century through the development of many standards to ensure the effective application of this process. The basis from the beginning was during manufacturing of the aircraft itself to ensure the presence of replicate systems and alternative systems to ensure the secured operating of aircrafts and with the normal development it became inevitable applying of such process system in all fields of aviation to include the ground handling provided to aircraft to ensure safety as well as achieving the appropriate service time (Ground Time Turn Around).

In 2008, Egypt air Ground Sevices began in applying the integrated system of risk management in a scientific way in cooperation with the International Air Transport Association (IATA), this is for the company to be one of the first international companies that apply this system successfully which reflected on the company's reputation through the lower rates of delays and also reducing the value of insurance premiums as a result of improving the ground handling of aircraft after the application of the program.
\end{abstract}

